\title{
Research on Problems and solutions of the Chinese enterprises Cross-border M\&A
}

\author{
Rongsheng $L v^{1, a}$, Mengnan $\mathrm{Li}^{2, \mathrm{~b}}$ \\ ${ }^{1}$ School of Management, Tianjin University of Technology, Tianjin, China \\ ${ }^{2}$ School of Management, Tianjin University of Technology, Tianjin, China \\ a534294697@qq.com, blimengnan325@163.com
}

Keywords: Chinese enterprises, cross-border M\&A, problems, countermeasure

\begin{abstract}
During the last Economic Crisis period, many well-known enterprises of developed countries faced survival challenges, which provided unforeseeable opportunities for China's cross-border M\&A. Therefore, in the post-crisis period, the researches on cross-border M\&A of Chinese enterprises have a greater realistic significance. This paper focuses on the Chinese enterprises' motivation and status in cross-border M\&A, points out the existing problems China's enterprises faced in their cross-border M\&A process, and discusses the opportunities and challenges that the crisis provided Chinese enterprises cross-border M\&A. This paper also puts forward some countermeasures for the existing problems of Chinese cross-border M\&A at the present stage. Finally it provides some valuable examples of the Chinese enterprises cross-border M\&A cases.
\end{abstract}

\section{Introduction}

The basic meaning of cross-border M\&A is that enterprise buys the whole assets from another country or performs the completely operation and control of the enterprise in some sort of purpose, according to a certain channels and means of payment. Fromyou can see, cross-border M\&A involves two or more than countriesenterprise, the "one country" is mergers or acquisitions enterprise, the "another country" is merger called target enterprise. This channel includesM\&Aenterprise invests directly to the target enterprise or mergers subsidiary from the target location. Hereis the term of payment, including cash, loans from financial institutions, and shares in stocks and bonds.[1]Chinese enterprises' cross-border merger and acquisition (M\&A) originated in the fifth wave of global M\&A and has been developing nearly 30 years. During the long-term development of cross-border M\&A,Chinese enterprises have made some achievements, but in terms of speed and the scale of M\&A, they fall far behind developed countries. The lack of internationalization experience and adverse environmental factors restricts the rapid growth of Chinese enterprisescross-border M\&A development. In order to carry out cross-border M\&A effectively, Chinese enterprises have been making changes in their work.[2]

\section{Analysis of Motivation and Current Problems of Chinses Cross-border M\&A}

\section{The Motivations of Chinese Cross-border M\&A}

Find natural resources. Resources ownership has an important strategic position in national development, which directly affects the degree of economic development. Reviewing the whole human history, there are accessing to natural resources caused by the war. With the continuous development of economy, the demand for natural resources from all over the world is increasing, and companies adopt the way of cross-border M\&A to hunger for resources.

Bypass the trade barriers. As Chinese economic strength rising, the fear of western countries on Chinese economic development has been increasing. They regardChina as the biggest competitorand think that Chinese economic development will threat to the interests of their country. To restrict the development of Chinese economy, other countries have unfair treatment against Chinese exports, ensure dumping investigation and foreign trade friction intensified trend. [3]So Chinese-foreign trade situation is not optimistic. Whether the final dumping cases are true, this 
played a serious obstacle on the development of Chinese-foreign trade. To develop one of the Chinese economic'rapid of foreign trade, transnational M\&A become a best choice for export. By means of enterprises cross-border M\&A to gain the foreign investment, not only it can complete enterprise development goals, but also can bypass harsh trade barriers of the developed countries. [4]

Acquire the core technology. "Introduction" and "going out" are two complementary strategies. After a long-term government attention to the strategy of "introducing", China has become the world's largest FDI country. This strategy can make Chinese enterprises develop to a certain extent, but also exposed more worries. If enterprises want to survive from the fierce competition in today's society, the core technology is indispensable. Only leading to master the core technology is the enterprise survival tips. However, independent research and development for enterprise core technology need not only a long time to process, but also a lot of money for support.

\section{An Analysis on the Problems of Chinese Multinational M\&A}

The reasonable formulation of the strategic planning. Because of asymmetric information and lack of target enterprise long-term systematic study, it makes Chinese enterprises not be accurately grasp the target enterprise's real business level and financial situation, and it also makes acquisitions have a lot of potential risks. Appreciation for opening the company aggressively buying American companies, unfortunate marriage causes the company finally defeated and flees with huge losses. For the enterprise in the acquisition of foreign enterprises in China, if you can't do it in a planned way, it will be likely in the 1980s to the acquisition of us companies at the same end

The inadequacy of ability of cultural integration. Relative to the domestic enterprises M\&A, cross-border M\&A involves not only the enterprise culture, but also the national culture. Therefore, culture is very important in the field of cross-border M\&A. Cultural Taylor gave the definition of culture: the founders of the so-called culture, its wide ethnographic sense is the knowledge, belief, art, morals, law, custom, and anyone as members of the society and get all ability and habits of the composite overall. Due to the body of the enterprise transnational M\&A belonging to different countries, they have different customs, language and religion, bound to lead to enterprise core values and the view is different.[5]

The lack of intermediary service structure. Cross-border M\&A is a complex activity, in terms of accounting firms, law firms, assets evaluation agencies and investment banks and other service agencies work closely to complete. [6]From the target enterprises choose to the final integration problems, I trequires the participation of intermediary service structure. Service agencies makes the M\&A target enterprise not only accurately grasp M\&A subject of financial and management status, but also makes the target enterprise M\&A subject more understanding of national policy and law, so as to achieve lower transaction and integration costs and avoid the risks.

\section{Countermeasures and Suggestions to Accelerate Development of Chinese Cross-border M\&A}

In the new period, the good investment environment at home and abroad provides hitherto unknown opportunities for Chinese transnational M\&A, faced with the opportunities we should keep a cool head, summarizes the development process of Chinese cross-border M\&A's problems and shortcomings in 20 years, puts forward the macro and micro two levels countermeasures and suggestions to promote China transnational M\&A with the rapid development of the health.

Countermeasures and Suggestions at Macro Level. The transformation of government functions, enable enterprises to become the real market corpus. After 30 years of reform and opening up, Chinese enterprises have already made considerable progress, but compared with developed countries, the international competitiveness of enterprises is insufficient, in control or the core technology, the enterprise management and operation has certain defects. Chinese companies want to survive in the fierce competition in the market; we must go out of the country to conduct cross-border M\&A. However, if enterprises want to improve their ability through cross-border M\&A, they must undertake reform, especially the state-owned enterprises. We should make the enterprise real trend market, speak according to the requirement of market economy, and adjust its strategic development goals according to the price mechanism and competition mechanism. Only 
the enterprises do become the true masters of talent market, transnational M\&A of Chinese enterprises improve the success rate.

The improvement of the policies and regulations In order to promote the rapid development of Chinese enterprises transnational M\&A, the government should formulate international standards of transnational merger and acquisition policy and regulations as soon as possible. The policy includes the following several aspects: first, continue to deepen the reform of the examination and approval of M\&A subject, and establish a unified national examination and approval department.Urgent approval of enterprise the government should open a green channel to avoid the loss because of the government work efficiency and the optimal timing of M\&A. Second, the government should provide more preferential policies to support for cross-border M\&A. In relationship to the national economy and people's livelihood low interest, government should loan reductions of transnational M\&A, as well as the transnational merger and acquisition enterprise reduction of enterprise income tax. Third, expand financing channels. By the China banking regulatory commission issued new policy, allow domestic banking cross-border M\&A of the enterprise, provide large amounts of money support, meet the demand of enterprise funds, encourage enterprises with strength, and carry on the listed financing.

Countermeasures and Suggestions at Micro Level. Set the strategic and practical planning Foreign and the domestic economic situation of Chinese multinational M\&A provides ideal investment environment, but the enterprise must suit their own situation and make detailed planning of M\&A. Before M\&A, they should know operating condition of the target enterprise, enterprise culture and the target country's legal policy system aspects, and understand the target enterprise.

Pay attention to cultural integration Unlike domestic M\&A, cross-border M\&A is a different political body, it will inevitably involve national differences, regional differences and cultural differences, if it is not handled properly, it will have a multiplier effect of enterprise culture, and enterprise culture will inevitably affect the smooth implementation of the enterprise transnational merger and acquisition. In order to ensure the transnational M\&A smoothly, Chinese enterprises must strengthen the following several aspects to pay attention to the cultural integration: first of all, managers of enterprises M\&A, object should be a careful study of cultural and historical conditions, in order to be better to understand the culture of the target enterprise characteristics, the method and the progress of cultural are integrated. Second, understand the cultural conflict correctly. Facing the cultural conflict is a kind of common phenomenon; we should confront the enterprise cultural differences, and we should not to be a particular culture as the measure of right and wrong. Finally, use inclusive mentality to treat cultural differences.

\section{Summary}

With reforming and opening up in deep and the continuous development of the "going out " strategy, transnational M\&A has been the main way to the foreign direct investment. After nearly 30 years of development, Chinese cross-border M\&A whether in their scale or the amount of them has obtained considerable development, it can be said that Chinese cross-border M\&A has made gratifying Results. However, compared with transnational merger history of developed countries in hundreds of years, Chinese cross-border M\&A's achievements are still very small. Less experience in M\&A, lack of overall planning and enterprises' strength and more than a series of problems make Chinese transnational merger taste the bitterness of failure number.

The global financial crisis in 2008, it caused all countries' economy affected in different degree, enterprise stock prices slashed, lacked funding to normal operation, and made some foreign enterprise face the threat of bankruptcy. Developed countries reduce the barriers to entry of multinational M\&A to go out of the crises as soon as possible. It can be said that the financial crisis provides unprecedented opportunities for Chinese multinational M\&A. Opportunities and challenges both exist, however, we are actively involved in cross-border M\&A process, it should be kept a cool head, not only see the opportunities clearly, but calmly realize this two-edged weapon brings risk. Only we fully recognize that the current all situations can find out the defects of 
Chinese cross-border M\&A process, and work out the solution to the problem, thus to improve the success rate of transnational M\&A in China.

\section{References}

[1] Hymer SH. TheInternational Operations of National Firms:A Study of DirectForeign Investment.Cambridge, MITPress, 1960.

[2] ZejanMC.NewVenturesorAcquisitions:TheChoiceofSwedishMultinationalEnterprises. Journalof IndustrialEconomias, 1990, (1).

[3] KearneyAT.Corporate Marriage:Blight or Bliss A Mono-graph on Post-Merger Integration. Chicago:AT Kearney,1999.

[4] Devigne D., Vanacker T., Manigart S., et al. The Role of Domestic and Cross-Border Venture Capital Investors in the Growth of Portfolio Companies. Small Business Economics, 2013, $40(3): 553-573$

[5] Alfaro L.,Chanda A.,Kalemli-Ozcan S., et al. Does Foreign Direct Investment Promote Growth? Exploring the Role ofFinan-cial Markets On Linkages.Journal of Development Economics, 2010, 91( 2) : 242-256.

[6] Erel I., Liao R. C., Weisbach M. S. Determinants of Cross-Border Mergers and Acquisitions. The Journal of Finance, 2012, 67( 3) : 1045-1082. 